\title{
An integrated flask sample collection system for greenhouse gas measurements
}

\author{
J. Turnbull ${ }^{1,2}$, D. Guenther ${ }^{2,3}$, A. Karion ${ }^{2,3}$, C. Sweeney ${ }^{2,3}$, E. Anderson ${ }^{2,3}$, A. Andrews ${ }^{3}$, J. Kofler ${ }^{2,3}$, N. Miles ${ }^{4}$, \\ T. Newberger ${ }^{2,3}$, S. Richardson ${ }^{4}$, and P. Tans ${ }^{3}$ \\ ${ }^{1}$ National Isotope Center, GNS Science, Lower Hutt, New Zealand \\ ${ }^{2}$ CIRES, University of Colorado at Boulder, Boulder, CO, USA \\ ${ }^{3}$ NOAA/ESRL, Boulder, CO, USA \\ ${ }^{4}$ Pennsylvania State University, University Park, PA, USA \\ Correspondence to: J. Turnbull (j.turnbull@gns.cri.nz)
}

Received: 24 May 2012 - Published in Atmos. Meas. Tech. Discuss.: 8 June 2012

Revised: 14 September 2012 - Accepted: 14 September 2012 - Published: 28 September 2012

\begin{abstract}
A one hour integrated flask sampling system to collect air in automated NOAA/ESRL 12-flask packages is described. The integrating compressor system uses a mass flow controller to regulate the flow of air through a 151 volume, thus providing a mixture of air collected over an hourlong period. By beginning with a high flow rate of 3.8 standard liters per minute and gradually decreasing the flow rate over time to 0.29 standard liters per minute it is possible to obtain a nearly uniformly time averaged sample of air and collect it into a pressurized 0.71 flask. The weighting function determining the air mixture obtained is described in detail. Laboratory and field tests demonstrate that the integrated sample approximates a simple mean of air collected during the one-hour sampling time.
\end{abstract}

\section{Introduction}

Atmospheric measurements of greenhouse and other trace gases are important to understanding the global carbon cycle, climate change and air quality problems. Due to the extreme accuracy required to quantify global, regional and local impacts on the mole fractions of these gases, especially in the case of long-lived greenhouse gases, flask measurements can play an essential role. Flask samples allow a single instrument with calibration standards tied directly to the World Meteorological Organization (WMO) to measure samples from many different locations (e.g. Conway et al., 2011; Brand, 2009). With flasks, small changes observed between one location and the next can be easily detected, whereas it may be difficult to keep multiple in situ instruments calibrated. These flask samples must be collected using a method that allows accurate, unbiased determination of the species of interest, and the samples must be collected in such a way that the results can be interpreted in terms of the regional and/or global atmosphere. Flask samples are typically collected as nearly instantaneous grab samples, whereby a flask is filled over a period of less than one minute into a pre-flushed or pre-evacuated flask (e.g. Conway et al., 1994, 2011; Brand, 2009). However, there can be substantial short-term variability in mole fractions of greenhouse gases at many locations, particularly at urban and other polluted sites. Grab samples may therefore also be difficult to interpret, particularly when the interpretation requires convolution with models and meteorological data which is typically available with time steps of one to three hours. Ongoing comparison of flask and in situ measurements is also a key part of data quality assurance for both types of measurement, yet comparisons are often compromised by the difficulty in matching the exact timing of the flask air collection with in situ measurements. Integrated flask samples can dramatically reduce the impact of small timing errors on these comparisons.

This paper describes an integrating compressor flask sample collection system (IC) to obtain air samples integrated over one hour. The IC is designed to be as simple as possible, while achieving the goal of collecting an integrated sample that is not contaminated, fractionated or otherwise altered during the collection process. The flasks are measured 
for more than 50 gases and isotopologues, and the sample air must remain unaltered for all of these species. Therefore, wherever possible, parts that have already been tested for use with these gases are selected. Flexibility in the design, so that the integration time can be varied easily, is also an important consideration, as is the ability to remotely and automatically trigger sampling.

\section{Sampler design and description}

First we describe the principles and overview of the IC, and then describe each part in detail. Figure 1 shows the overall system. The air enters from the inlet through $3 / 8$ inch outside diameter Synflex 1300 tubing (Eaton Corporation, Ohio, USA), and then passes through a dryer unit, removing the bulk of the water from the air. Then the air passes through a 15 liter (l) spherical mixing chamber - the heart of the IC. Two pumps (N811 pump, KNF, New Jersey, USA) and a mass flow controller (MKS1479, MKS, Massachusetts, USA) are used to regulate the flow of air through the mixing chamber. A bypass valve can be used to override the mass flow controller and allow a higher flow rate, which is 3.8 standard liters per minute (SLPM) and was determined from a temporary flow meter. All tubing within the IC is $1 / 8$ inch outside diameter stainless steel. During the hourlong integration period, the air is flushed out through flasks contained in the NOAA/ESRL 12-flask Programmable Flask Package (PFP (http://www.esrl.noaa.gov/gmd/ccgg/aircraft/ index.html; Sweeney et al., 2012), and at the end of the integration time, the flasks are filled and pressurized with air from the mixing chamber. In standby mode, when no sample is being collected, air is flushed through the mixing chamber and pumps, and vented to atmosphere via a standby vent valve.

This design was chosen over several possible alternatives, such as (1) a large volume or bag that is evacuated and then air is allowed to gradually enter over the designated time period; (2) a syringe like system where the integrating volume is initially small, and the volume is increased linearly through the integrating time period. Although these alternative designs may be conceptually simpler, they use components that have not been tested for the suite of gases of interest and extensive testing would be needed to ensure that the trace gas composition was not altered. This is of particular concern for bags, in which the trace gas composition of air could be altered by absorption/desorption due to the evacuation procedure or the bag material.

\subsection{Mixing chamber}

The mixing chamber is an approximately 151 spherical volume of electro-polished stainless steel made by Restek Corporation (Pennsylvania, USA). A 1/8 inch outside diameter dip tube is inserted into the volume, so that air enters the

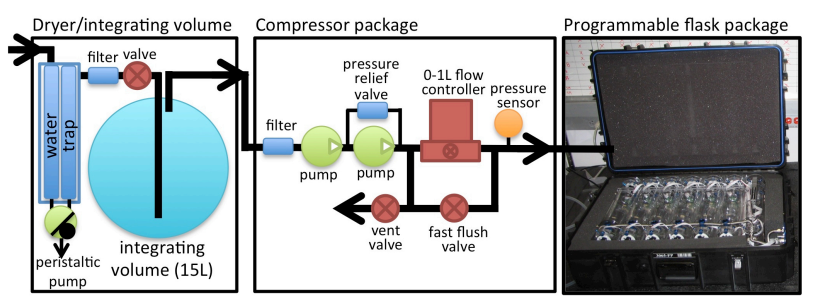

Fig. 1. Integrating compressor flask sample collection system schematic.

volume at the base, and flows out from the top, thus ensuring well-mixed conditions inside the volume. First, we tested the mixing chamber to ensure that mixing is nearly complete throughout the fill time and thus can be predicted using a simple $e$-folding model. The $e$-folding model of a well-mixed volume predicts a mean lifetime (residence time, $\tau$ ) of any given parcel of air in the mixing chamber of

$\tau=1 / k$

where $k$ is the rate constant for the removal of the air from the volume; $k$ is determined by the flow rate $f$ and the volume of the mixing chamber $v$ such that

$k=\frac{f}{v}$.

When an air parcel with an initial mass $m\left(t_{0}\right)$ enters the volume at time $t_{0}$, the amount of that air parcel remaining at a later time $t$ is determined according to the $e$-folding model as

$m(t)=m\left(t_{0}\right) e^{-k\left(t-t_{0}\right)}$.

To test the mixing inside the volume, two cylinders, one of dried natural air (natural air) with $378.95 \mathrm{ppm}\left(\right.$ moles $\mathrm{CO}_{2}$ per mole dry air) of $\mathrm{CO}_{2}$, the other of air with no $\mathrm{CO}_{2}$ (zero air, produced by a commercial supplier by scrubbing of $\mathrm{CO}_{2}$ from natural air), were connected to the mixing chamber. In this arrangement, the $\mathrm{CO}_{2}$ mole fraction is a proxy for $m(t)$. The regulators were set to release cylinder air at slightly over atmospheric pressure with the excess pressure vented to the room, so that the air entering the IC was at room pressure $(850 \mathrm{hPa}$ at $1600 \mathrm{~m}$ a.s.l. in Boulder, CO). The air then passed through the mixing chamber and pumping system, and the outlet was connected to a cavity ring-down spectrometer (CRDS, Model G1301, Picarro, California, USA; Crosson, 2008) continuously monitoring the $\mathrm{CO}_{2}$ mole fraction. Initially, natural air was flowed through the mixing chamber at the maximum flow rate of 3.8 SLPM until the CRDS measurement stabilised at $378.95 \mathrm{ppm}$. The incoming air was then switched to the zero air cylinder, and we observed the decay of the $\mathrm{CO}_{2}$ mole fraction while pumping at a known, constant flow rate of 3.8 SLPM (Fig. 2). The mole fraction decay fitted an exponential decay curve extremely 


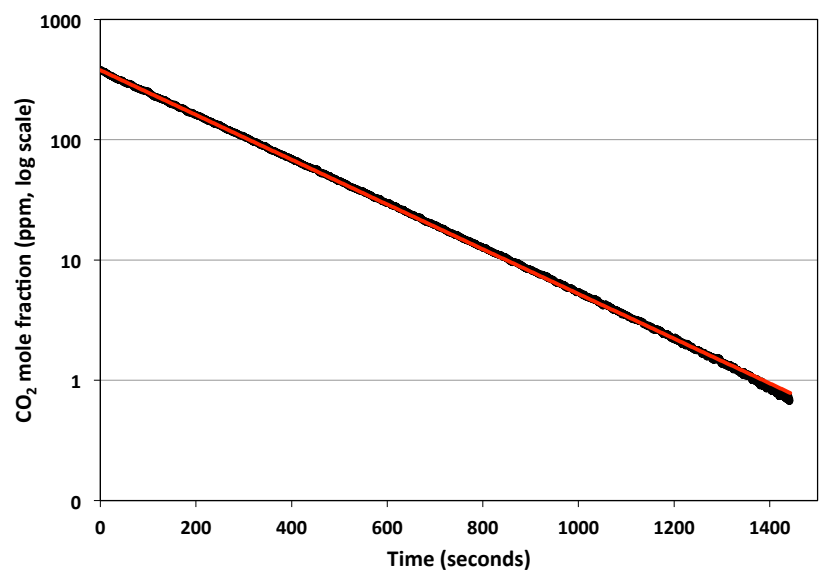

Fig. 2. Measured $\mathrm{CO}_{2}$ mole fraction through time, starting with "ambient" 378.95 ppm $\mathrm{CO}_{2}$ air inside integrating volume. Air entering the volume was switched to "zero" $0 \mathrm{ppm} \mathrm{CO}_{2}$ air at time zero. Flow rate was set at 3.8 SLPM.

well, and we determined $k=0.00428 \mathrm{~s}^{-1}$, which implies a mean lifetime $\tau=3.89 \mathrm{~min}$ and volume $v$ of 14.81, approximately equal to the nominal volume of the mixing chamber. This experiment confirms that air mixes well in the spherical integration volume, and follows a theoretical $e$-folding decay, dependent on flow rate and the size of the mixing chamber.

\subsection{Weighting function}

Ideally, the final mixture of air in the flask would have a flat, constant weighting function, such that at the end of a one-hour sampling interval, the mixing chamber would contain an equal amount of air from each minute of the hour, with $1.67 \%$ of the total air in the chamber having entered it in each minute of the hour. The 151 mixing chamber would therefore contain 0.251 of air from each of the $60 \mathrm{~min}$ of the hour (Fig. 3). However, the actual weighting function is determined by the flow rate and mixing chamber volume. If the flow rate is kept constant, the weighting function can be calculated from Eqs. (2) and (3). In this constant flow rate case, the final air mixture is dominated by air from the last part of the hour. The higher the flow rate, the steeper the weighting function, so that the final air mixture is more strongly dominated by the last part of the hour (4 SLPM case in Fig. 3). Lowering the flow rate results in a more even weighting function, but when the flow rate drops too low, some air from prior to the 60 -min interval will remain inside the flask (1 SLPM case in Fig. 3).

A perfectly even weighting function can be achieved if the flow rate is infinitely adjustable, starting with a very high flow rate and gradually dropping the flow rate through time. As the following equations cannot be integrated analytically, we demonstrate the concept using a time step of one minute. Of the air that entered the flask during the last minute of the one-hour interval $\left(m_{1}\left(t_{1}\right)\right)$, the amount remaining inside the

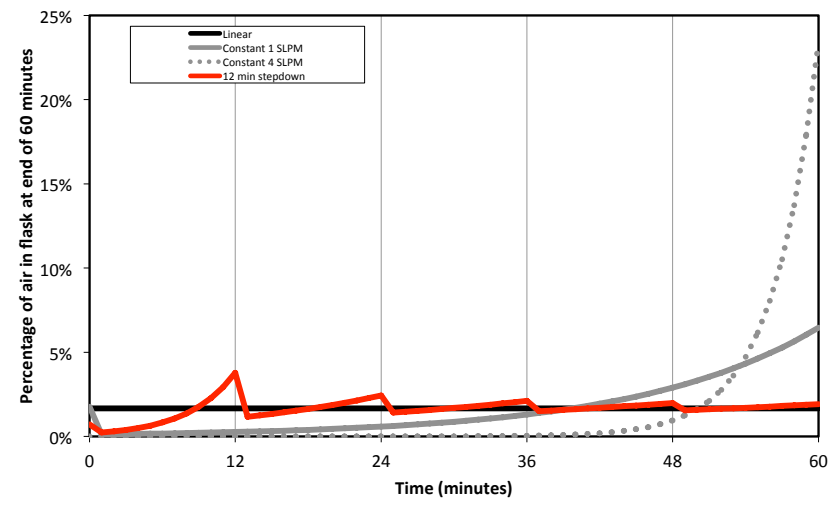

Fig. 3. Weighting function for air inside the 151 integrating volume after $60 \mathrm{~min}$, under different flow scenarios. Black line: ideal linear weighting function where each timestep contributes an equal amount to the final sample ( $1.67 \%$ from each minute). Solid and dotted grey lines: constant flow at 1 and 4 SLPM, respectively. Red line: the weighting function we selected changing the flow rate every $12 \mathrm{~min}$ from 3.8 SLPM to 1 SLPM to 0.55 SLPM to 0.38 SLPM to 0.29 SLPM. The value at minute zero for each curve is the sum total of all air remaining in the flask from times prior to the last $60 \mathrm{~min}$.

flask at the end of the one-hour interval (final time $t_{\mathrm{f}}$ ) is

$m_{1}\left(t_{\mathrm{f}}\right)=m_{1}\left(t_{1}\right) e^{-k_{1}\left(t_{\mathrm{f}}-t_{1}\right)}$

and the rate constant for the last time step $k_{1}$ depends on the flow rate $f_{1}$ during that last time step and the mixing chamber volume

$k_{1}=\frac{f_{1}}{v}$.

The initial amount of air $m_{1}\left(t_{1}\right)$ introduced during this last time step is a function of the flow rate and length of the time step $\Delta t$ (equal to $t_{\mathrm{f}}-t_{1}$ ), such that

$m_{1}\left(t_{1}\right)=f_{1} \cdot \Delta t$

and therefore

$m_{1}\left(t_{\mathrm{f}}\right)=f_{1} \cdot \Delta t e^{-\frac{f_{1}}{v} \Delta t}$.

Of the air that entered during the preceding minute $t_{1-1}$, the amount of air remaining at time $t_{\mathrm{f}}$ is

$m_{1-1}\left(t_{\mathrm{f}}\right)=f_{1-1} \cdot \Delta t e^{-\frac{\Delta t}{v} f_{\mathrm{l}-1}} e^{-\frac{\Delta t}{v} f_{\mathrm{l}}}$

and more generally,

$m_{1-n}\left(t_{\mathrm{f}}\right)=f_{1-n} . \Delta t e^{-\frac{\Delta t}{v} \sum f_{1-i}}$.

That is, the amount of air remaining from a given time step at the end of the hour is a function of the flow rate during that time step and of the flow rate in all the following time steps. 
To achieve a perfectly linear weighting function using a 151 volume, we would need to adjust the flow rate from an initial rate of more than 100000 SLPM to less than 0.01 SLPM at the end of the hour, which is not feasible with available equipment. Nor is it desirable, since pressures throughout the system would change dramatically, especially if the change in flow rate occurred throughout the entire length of sample tubing. We use a flow controller that adjusts between 0.1 and 1 SLPM, and by opening the bypass valve (Fig. 1), we can obtain a higher flow rate of 3.8 SLPM. In future upgrades to the system, we plan to use a 0.2-2 SLPM flow controller, and note that although flow controllers with larger dynamic range are available, the control is typically accurate to within only a few percent, so that accurate control at the low end of the range becomes problematic. We aim for a near-linear weighting function, changing the flow rate every $12 \mathrm{~min}$, with the initial flow rate at $3.8 \mathrm{SLPM}$, dropping down to 1 SLPM, 0.55 SLPM, 0.38 SLPM and finally 0.29 SLPM in the last $12 \mathrm{~min}$. This weighting function is shown as the red saw-tooth curve in Fig. 3. Each 12-min segment has equal weight $(20 \%)$, and air from prior to the start of the hour contributes $0.7 \%$ to the total. The weighting of individual minutes during the hour ranges from $0.2-3.8 \%$ with the largest variability in the weighting during the first $12 \mathrm{~min}$ of the hour.

The simple pumping system and long (typically $100 \mathrm{~m}$ ) inlet line means that when the flow rate changes, the lag time for air reaching the mixing chamber from the top of the inlet also changes. Air reaching the mixing chamber near the end of the hour has a residence time of $15 \mathrm{~min}$. Minimizing the residence time is thought to reduce the potential for wall effects, so future versions of the system will be built with modifications to keep the flow in the inlet line constant. This will be achieved by installing a constant flow rate flush pump upstream of the mixing chamber and venting the excess air. In the current configuration, we account for the lag time in the weighting function calculation.

We tested the integration parameters and weighting function in the laboratory, using the same setup described in Sect. 2.1.1. In this experiment, the flow rate was stepped down every $12 \mathrm{~min}$ of inlet time (Fig. 4). The air from a natural air cylinder with $363.5 \mathrm{ppm} \mathrm{CO}_{2}$ (measured on the CRDS instrument) was flushed through the system at 3.8 SLPM for $20 \mathrm{~min}$ prior to the start of the experiment. The incoming air was switched between the natural and zero air cylinders at several arbitrary times, shown as grey bars in Fig. 4. We then used our theoretical weighting function (Fig. 3) to predict the $\mathrm{CO}_{2}$ mole fraction at the end of our sampling time, and compared it with the measured $\mathrm{CO}_{2}$ mole fractions. The measured value on the CRDS instrument at the end of $60 \mathrm{~min}$ was $335.3 \mathrm{ppm}$; the expected value was $335.1 \mathrm{ppm}$. Furthermore, we calculated the expected $\mathrm{CO}_{2}$ mole fraction exiting the IC at each time step, and see good agreement between the expected and measured values (Fig. 4).

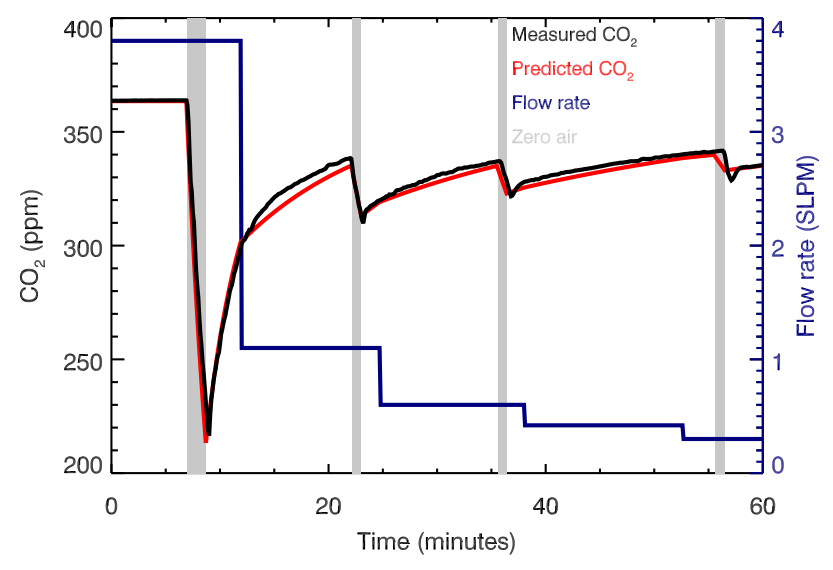

Fig. 4. Test of weighting function. Cylinder air at room pressure was flowed through the integrating system at the indicated flow rates (blue). Note that the flow rates in this experiment were slightly different than our standard protocol used in Fig. 3. Natural $363.5 \mathrm{ppm}$ $\mathrm{CO}_{2}$ air was flowed through the system for $20 \mathrm{~min}$ prior to the start of the experiment and during the experiment, except during the periods shaded in grey, when incoming air was switched to zero air. The measured $\mathrm{CO}_{2}$ mole fraction exiting the system is indicated in black, and was $335.3 \mathrm{ppm}$ at the end of the integrating time (60 min). Predicted values at each time step are shown in red, and the final predicted value was $335.1 \mathrm{ppm}$.

\subsection{Drying of air}

The air from the IC is eventually collected and pressurized to $275 \mathrm{kPa}$ in $0.7 \mathrm{~L}$ PFP flasks (Sect. 2.4). As pressurization may exacerbate problems with water vapor, the air is dried prior to entering the mixing chamber (Fig. 1). A thermoelectric chiller with two trapping loops and a temperature of $5^{\circ} \mathrm{C}$ (M\&C products ECP-20-2) is used. The air flows through both loops and a peristaltic pump removes condensed water. Sufficient water is removed to result in a maximum specific humidity of 0.0014 mole $\mathrm{H}_{2} \mathrm{O}$ per mole of dry air in the pressurized flasks. During high humidity periods, occasional problems with the chiller icing up and blocking air flow have been encountered.

The IC was tested for any change in $\mathrm{CO}_{2}$ mole fraction during drying. Using the same setup described in Sect. 2.1.1 (including the full integrating system), natural cylinder air was flowed through and measured using the CRDS. For this test, we added a magnesium perchlorate $\left(\mathrm{Mg}\left(\mathrm{ClO}_{4}\right)_{2}\right)$ trap just prior to the CRDS inlet so that no water correction was needed in the instrument's $\mathrm{CO}_{2}$ mole fraction determination. Although it is possible that the $\mathrm{Mg}\left(\mathrm{ClO}_{4}\right)_{2}$ trap may introduce artifacts, any such bias is expected to be consistent across all the tests. Four tests were performed: (1) dry natural cylinder air was flowed through the IC with the thermoelectric chiller completely removed; (2) dry natural cylinder air was flowed through the IC with the chiller included; (3) natural cylinder air was wetted by bubbling through a flask of 


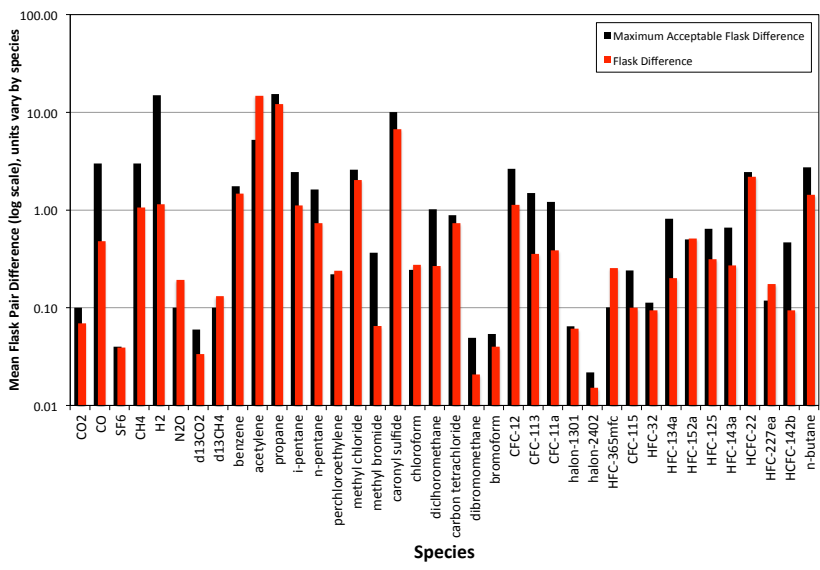

Fig. 5. Mean flask pair differences, typically averaged over 12 flask pairs. Measured mean pair differences for each species are shown in red, and the acceptable maximum pair difference is shown in black. Vertical axis uses a log scale for clarity, units vary by species. $\mathrm{CO}_{2}$ is reported in ppm, $\mathrm{CO}, \mathrm{CH}_{4}, \mathrm{~N}_{2} \mathrm{O}$ and $\mathrm{H}_{2}$ are in ppb, $\delta{ }^{13} \mathrm{CO}_{2}$ and $\delta^{13} \mathrm{CH}_{4}$ are in \%o, all other species are in reported in ppt.

distilled water and flowed through the IC with the chiller in place but not switched on; (4) same as (3) but with the chiller switched on. In these tests, the air was flowed at a constant rate of either the high 3.8 SLPM or low 0.29 SLPM flow rate, and the $\mathrm{CO}_{2}$ mole fraction entering the CRDS was monitored through time. The $\mathrm{CO}_{2}$ mole fraction in all these tests varied by less than $0.06 \mathrm{ppm}$.

\subsection{Simultaneous filling of multiple flasks}

In order to provide enough air for measurement of $\sim 50$ trace gases and isotopes including ${ }^{14} \mathrm{CO}_{2}$, two $0.71 \mathrm{PFP}$ flasks filled to $275 \mathrm{kPa}$ are collected as a pair. The PFP firmware was initially designed to fill a single flask at a time, and in many cases, the paired flasks for ${ }^{14} \mathrm{CO}_{2}$ have been collected sequentially (Turnbull et al., 2006; Miller et al., 2012), assuming that variability in the air during the few minutes between flask fills is negligible relative to the ${ }^{14} \mathrm{CO}_{2}$ measurement uncertainty. However, the IC allows the opportunity to override the standard flask filling firmware, and simultaneously flush and fill two flasks. During the one-hour integration period, both flasks are opened, and the air exiting the IC is flushed through the flasks and out into the room. Once the one-hour integration period is complete, the back valves on the flasks are closed and the pumps pressurize both flasks to $275 \mathrm{kPa}$. The IC remains open to the inlet and at the last flow rate of 0.29 SLPM during the pressurization so that the air collected in the flasks actually contains a small amount of air ( $1 \%$ of the total) from the 61 st minute of the interval. This is necessary with the pumps currently used, as they are unable to pressurize the flasks sufficiently when the pressure inside the 151 spherical volume drops too low. The impact of this

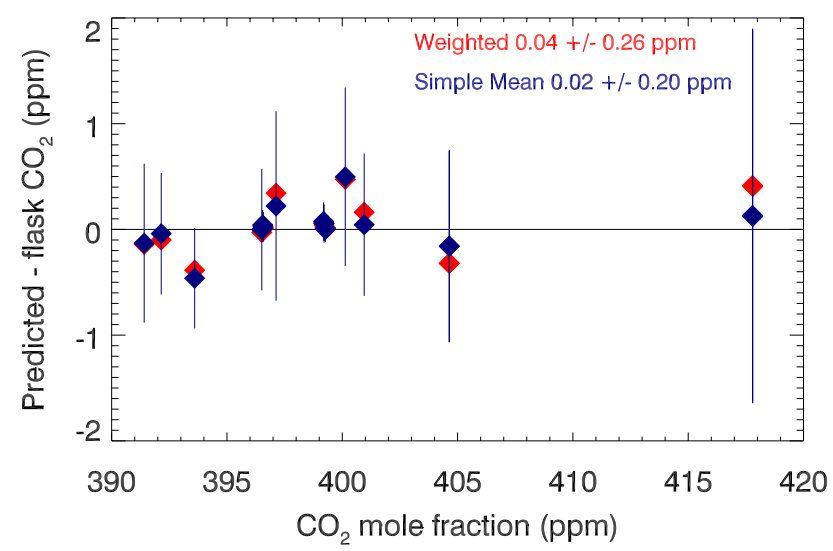

Fig. 6. Difference between predicted and measured flask $\mathrm{CO}_{2}$ mole fraction, plotted against the $\mathrm{CO}_{2}$ mole fraction. Predicted mole fractions were calculated from in situ $(\sim 2 \mathrm{~s}) \mathrm{CO}_{2}$ measurements. Red points use the full weighting function to calculate the predicted $\mathrm{CO}_{2}$ mole fraction; blue points use a simple average of the in situ values during the flask sampling time. Error bars on the blue points indicate the standard deviation of the in situ measurements during the sampling time.

on the final mixture is negligible across a reasonable range of mole fractions.

For most samples, one flask of the pair is reserved for ${ }^{14} \mathrm{CO}_{2}$ measurement, and the second flask is measured for all other species. However, for a small subset of 12 samples where ${ }^{14} \mathrm{CO}_{2}$ measurement was not needed, both flasks of the pair were measured for all other species (Fig. 5). Pair agreement is excellent for all species measured and is as good as or better than the acceptance criteria used for the NOAA/ESRL Cooperative Sampling Network (Montzka et al., 1993; Zhao and Tans, 2006; Conway et al., 1994; Komhyr et al., 1985; B. R. Miller, personal communication, 2012). We calculate the mean pair difference as the mean of the absolute values of the pair differences, and the uncertainty as the onesigma scatter of those pair differences. For $\mathrm{CO}_{2}$, the mean pair difference is $0.07 \pm 0.08 \mathrm{ppm}$, versus the acceptable pair difference cutoff of $0.1 \mathrm{ppm}$; mean $\mathrm{CO}$ pair difference is $0.5 \pm 0.4 \mathrm{ppb}$ versus acceptable pair difference of $3 \mathrm{ppb}$, and mean $\mathrm{CH}_{4}$ pair difference is $1 \pm 1 \mathrm{ppb}$ versus the acceptable pair difference of $3 \mathrm{ppb}$.

\subsection{Remote operation of IC}

The IC is controlled by a CR1000 Campbell Scientific Datalogger and Loggernet software (Utah, USA), which control sampling times, changes in flow rate, and other sampling parameters. The datalogger is remotely operated and monitored via cellular modem. In the current configuration, the software is set to automatically sample beginning at 03:00 p.m. local standard time (when the boundary layer is well mixed and most easily modeled) each day. Flasks are oversampled the next day if a post-sampling analysis of meteorological 


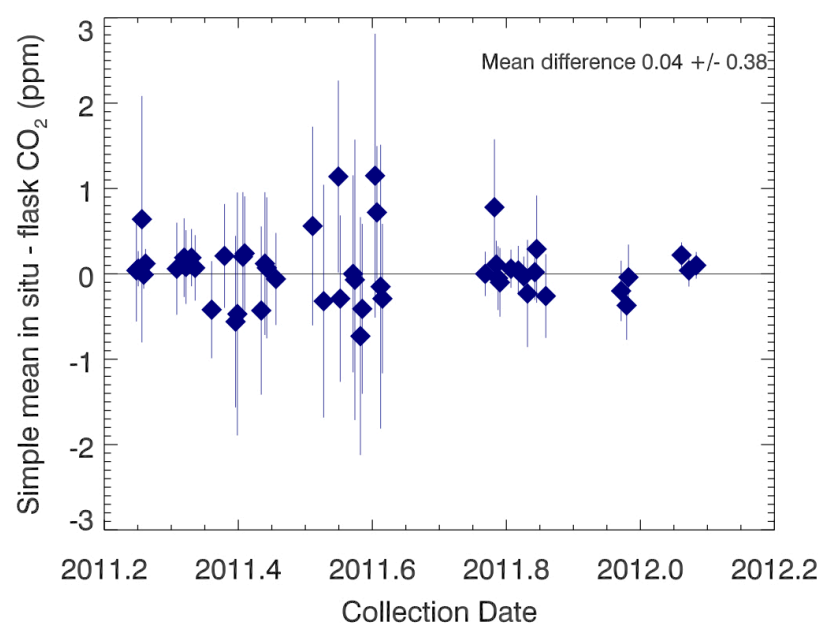

Fig. 7. Difference between in situ mean and flask $\mathrm{CO}_{2}$ mole fraction for 50 flasks sampled at two sites near Indianapolis. Error bars are the standard deviation of the in situ values during the sampling time. Mean difference is $0.04 \mathrm{ppm}$.

conditions does not meet pre-defined criteria. Oversampling involves expunging the existing sample by flushing, then flushing and filling with the new sample as usual. We examined the agreement between in situ and flask measurements for flasks that were oversampled and those that were not oversampled, and found no discernable difference. One limitation of the oversampling strategy is that if a flask flushing problem occurred, it would be difficult to identify the problem (versus a more typical strategy whereby residual fill gas in the flasks can be identified by its abnormal mole fractions; Conway et al., 2011).

\subsection{Field testing}

Two IC units were deployed near Indianapolis, USA on cell phone towers, alongside cavity ring-down spectrometers that continuously measure $\mathrm{CO}_{2}$ in situ. The two systems are designed to complement each other, with the continuous measurements providing high time resolution of $\mathrm{CO}_{2}$ mole fractions, and the flasks providing measurement of 50 species, many of which cannot be measured continuously or in situ. In addition, comparison between the two techniques provides a quality check of both instruments, and ensures that instruments at different sites are on the same scale. The in situ measurements utilise CRDS (Picarro model G2401) measuring $\mathrm{CO}_{2}, \mathrm{CO}, \mathrm{CH}_{4}$ and $\mathrm{H}_{2} \mathrm{O}$, with a configuration similar to that described by Richardson et al. (2012), except that the air is also dried prior to measurement. The in situ and flask systems sample air from separate inlet lines located immediately adjacent to one another at the same tower height. Both flask and in situ data are corrected for the time offset of air flowing from the inlet to the instrument, with different time offsets for the flask and in situ instruments. We examine all available measurements where flask samples were collected and the in situ instrument collected $\mathrm{CO}_{2}$ data during the entire hour of integrated flask sampling. A total of 50 paired measurements were collected between April 2011 and January 2012 at two different tower sites, one urban and one rural.

First, we examine a randomly selected subset $(n=12$, selected as it is too time-consuming to look at all results in this way) of samples in detail, comparing with the in situ $\mathrm{CRDS} \mathrm{CO}_{2}$ measurements made approximately every 2 seconds. For each of these samples, we calculate the predicted flask $\mathrm{CO}_{2}$ mole fraction from the in situ data, first explicitly using our weighting function, and second using a simple mean of all in situ measurements made during the sampling time. The weighted and simple means give similar results across a range observed of $\mathrm{CO}_{2}$ mole fractions and across observed $\mathrm{CO}_{2}$ variability during the sampling time (Fig. 6). The mean difference between predicted and measured flask $\mathrm{CO}_{2}$ mole fraction (calculated as predicted minus flask value) is $0.04 \pm 0.26 \mathrm{ppm}$ when the weighting function is used, and $0.02 \pm 0.20 \mathrm{ppm}$ when the simple mean is used. We conclude that the simple mean of in situ measurements is sufficient to approximate the weighting function.

We then examine all 50 paired flask/in situ measurements, using the simple mean of the in situ measurements. The comparison is made for all available flask samples when the sideby-side in situ system made measurements for the full hour during which the flask sample was collected. The mean difference is $0.04 \pm 0.38 \mathrm{ppm}$ (Fig. 7). The largest differences occur during times when the $\mathrm{CO}_{2}$ variability within the hour is high. Of particular note are several samples collected during summer 2011 where the in situ-flask difference is greater than $1 \mathrm{ppm}$. These samples were collected at the rural site during periods of strong photosynthetic drawdown and with high variability in the measured in situ $\mathrm{CO}_{2}$ mole fraction during the hour. In many other instances of high variability, the in situ-flask agreement was excellent, and suggests that the large difference for these samples indicates a problem with either the flask or in situ measurement, which has not yet been resolved.

Acknowledgements. Flask measurements and field logistics were performed by NOAA/ESRL/CCGG. Funding for this project was provided by the National Institute of Standards and Technology Grant number 60NANB10D023. We thank the two reviewers and the AMT editor for their helpful advice in improving this manuscript.

Edited by: D. Griffith 


\section{References}

Brand, W. A.: GAW Report No. 194, 15th WMO/IAEA meeting of experts on carbon dioxide, other greenhouse gases and related tracers measurement techniques, Jena, Germany 7-10 September 2009, Rep. 1553, 51 pp., World Meteorological Organization, 2009.

Conway, T. J., Tans, P. P., Waterman, L., Thoning, K. W., Kitzis, D., Masarie, K. A., and Zhang, N.: Evidence for interannual variability of the carbon cycle from the National Oceanic and Atmospheric Administration/Climate Monitoring and Diagnostics Laboratory global air sampling network, J. Geophys. Res., 99, 22831-22855, 1994.

Conway, T. J., Lang, P. M., and Masarie, K. A.: Atmospheric carbon dioxide dry air mole fractions from the NOAA/ESRL Carbon Cycle Global Cooperative Network, 1968-2010, version 201106-21, available at: ftp://ftp.cmdl.noaa.gov/ccg/co2/flask/event/ (last access: 1 April 2012), 2011.

Crosson, E. R.: A cavity ring-down analyzer for measuring atmospheric levels of methane, carbon dioxide, and water vapor, Appl. Phys. B-Lasers O., 92, 403-408, 2008.

Komhyr, W. D., Gammon, R., Harris, T., Waterman, L., Conway, T. J., Taylor, W., and Thoning, K. W.: Global atmospheric CO distribution and variations from 1968-1982 NOAA/GMCC CO flask sample data, J. Geophys. Res., 90, 5567-5596, 1985.

Miller, J. B., Lehman, S. J., Montzka, S. A., Sweeney, C., Miller, B. R., Wolak, C., Dlugokencky, E. J., Southon, J. R., Turnbull, J. C., and Tans, P. P.: Linking emissions of fossil fuel $\mathrm{CO}_{2}$ and other anthropogenic trace gases using atmospheric ${ }^{14} \mathrm{CO}_{2}$, J. Geophys. Res., 117, D08302, doi:10.1029/2011JD017048, 2012.
Montzka, S. A., Myers, R. C., Butler, J. H., Elkins, J. W., and Cummings, S.: Global tropospheric distribution and calibration scale of HCFC-22, Geophys. Res. Lett., 20, 703-706, 1993.

Richardson, S., Miles, J. N. L., Davis, K. J., Crosson, E. R., Rella, C. W., and Andrews, A. E.: Field testing of cavity ring-down spectroscopic analyzers measuring carbon dioxide and water vapor, J. Atmos. Ocean.-Tech., 29, 397-406, 2012.

Sweeney, C., Karion, A., Wolter, S., Neff, D., Higgs, J. A., Heller, M., Guenther, D., Miller, B. R., Montzka, S. A., Miller, J. B., Conway, T. J., Dlugokencky, E. J., Novelli, P. C., Masarie, K. A., Oltmans, S., and Tans, P. P.: Three dimensional distribution of $\mathrm{CO}_{2}$ across North America from the NOAA/ESRL greenhouse gas aircraft network, in preparation, 2012.

Turnbull, J. C., Miller, J. B., Lehman, S. J., Tans, P. P., Sparks, R. J., and Southon, J. R.: Comparison of ${ }^{14} \mathrm{CO}_{2}, \mathrm{CO}$ and $\mathrm{SF}_{6}$ as tracers for determination of recently added fossil fuel $\mathrm{CO}_{2}$ in the atmosphere and implications for biological $\mathrm{CO}_{2}$ exchange, Geophys. Res. Lett., 33, L01817, doi:10.1029/2005GL024213, 2006.

Zhao, C. and Tans, P. P.: Estimating uncertainty of the WMO mole fraction scale for carbon dioxide in air, J. Geophys. Res., D08S09, doi:10.1029/2005JD006003, 2006. 